\title{
European evidence based consensus on the diagnosis and management of Crohn's disease: definitions and diagnosis
}

\author{
E F Stange, S P L Travis, S Vermeire, C Beglinger, L Kupcinskas, K Geboes, A Barakauskiene, \\ V Villanacci, A Von Herbay, B F Warren, C Gasche, H Tilg, Stefan W Schreiber, J Schölmerich, \\ W Reinisch, for the European Crohn's and Colitis Organisation (ECCO)
}

\subsection{INTRODUCTION}

Crohn's disease $(\mathrm{CD}$ ( is a lifelong disease arising from an interaction between genetic and environmental factors, but seen predominantly in the developed countries of the world. The precise aetiology is unknown and therefore a causal treatment is not yet available. Within Europe there is a distinct north-south gradient, but the incidence seems to have increased in southern countries in recent years. ${ }^{1}$ Many patients live with a considerable symptom burden despite medical treatment in the hope that the aetiology of the disease will shortly be discovered and curative therapies emerge. Although this seems likely to happen at some time in the next decade, clinicians have to advise patients on the basis of information available today rather than an unknown future. Despite a multiplicity of randomised trials there will always be many questions that can only be answered by the exercise of judgement and opinion. This leads to differences in practice between clinicians, which may be brought into sharp relief by differences in emphasis between countries.

The consensus endeavours to address these differences. The consensus is not meant to supersede the guidelines of different countries (such as those from the UK, ${ }^{2}$ Germany, ${ }^{3}$ or France), which reach broadly the same conclusions as they are, after all, based on the same evidence. Rather, the aim of the consensus is to promote a European perspective on the management of CD and its dilemmas. As the development of guidelines is an expensive and time consuming process, it may help to avoid duplication of effort in the future. A consensus is also considered important because an increasing number of therapeutic trials are based in Europe, especially in eastern European countries where practice guidelines have yet to be published.

This document sets out the current European consensus on the diagnosis and management of CD, reached by the European Crohn's and Colitis Organisation (ECCO) at a meeting held in Prague on 24 September 2004. ECCO is a forum for specialists in inflammatory bowel disease (IBD) from 20 European countries. It was established in 2000 with the common purpose of promoting European views, clinical trials, and specialist training in inflammatory bowel disease. The consensus is grouped into three parts: definitions and diagnosis; current management; and management of special situations. This first section concerns aims and methods of the ut 2006;55(Suppl I):i1-i15. doi: 10.1136/gut.2005.081950a consensus, as well as diagnosis, pathology, and classification of $\mathrm{CD}$. The second section on current management includes treatment of active disease, maintenance of medically induced remission, and surgery of $\mathrm{CD}$. The third section on special situations in CD includes postoperative recurrence, fistulating disease, paediatrics, pregnancy, psychosomatics, extraintestinal manifestations, and alternative therapy.

The strategy to reach the consensus involved five steps:

(1) Relevant questions on each of 14 separate topics concerning diagnosis and treatment of CD were devised by the chairmen and their working party. The questions were focused on current practice and areas of controversy in the task force topic, sent around to the other chairmen to avoid duplication, and then to all participants in the consensus conference. Participants were asked to answer the questions based on their experience as well as evidence from the literature (Delphi procedure). ${ }^{4}$

(2) In parallel, the working parties performed a systematic literature search of their topic with the appropriate key words using Medline/Pubmed and the Cochrane database, as well as their own files. The evidence level was graded (table 1.1) according to the Oxford Centre for Evidence Based Medicine. ${ }^{5}$

(3) Provisional guideline statements on their topic were then written by the chairmen, based on answers to the questionnaire as well as the literature evidence and were circulated first among the working party and then among the participants.

(4) The working parties then met in Prague on the 23 September 2004 to agree the statements. On 24 September 61 participants gathered under the chairmanship of $\mathrm{E} F$ Stange to agree the final version of each guideline statement. Technically this was done by projecting the statements and revising them on screen until a consensus was reached. On one occasion, when the ECCO Board considered that a statement

Abbreviations: CD, Crohn's disease; CDAl, Crohn's disease activity index; CRP, $C$ reactive protein; $C T$, computed tomography; ECCO, European Crohn's and Colitis Organisation; ESR, erythrocyte sedimentation rate; IBD, inflammatory bowel disease; UC, ulcerative colitis; US, ultrasound; WCE, wireless capsule endoscopy
Accepted

21 December 2005 
was open to misinterpretation and failed accurately to reflect the text, all original participants were asked to vote on new wording by email. Consensus was defined as agreement by $>80 \%$ of participants, termed a consensus statement and numbered for convenience in the document. Each recommendation was graded (RG) according to the Oxford Centre for Evidence Based Medicine, ${ }^{5}$ based on the level of evidence (table 1.1).

(5) The final document on each topic was written by the chairmen in conjunction with their working party. Consensus guideline statements displayed in boxes are followed by comments on the evidence and opinion. Statements are intended to be read in context with qualifying comments and not read in isolation. The final text was edited for consistency of style by S P L Travis and E F Stange before being circulated and approved by the participants. In some areas the level of evidence is generally low, which reflects the paucity of randomised controlled trials. Consequently expert opinion is included where appropriate.

\subsection{Definitions}

Common agreement was reached about frequently used terms. While the significance of some terms (such as "early" or "pattern of relapse") are undetermined, such terms reflect clinical decision making (such as when to start immunomodulators). The arbitrariness of some of the definitions is recognised, but the consensus considers it useful to agree the terminology.

\subsubsection{Active disease}

For the purposes of this consensus, clinical disease activity is grouped into mild, moderate, and severe (table 1.2). These are not precisely defined entities. Most clinical trials in patients with active CD recruit patients with a Crohn's disease activity index $(\mathrm{CDAI})>220$. The fallibility of this threshold is illustrated by the high placebo response in recent trials of biological therapy $^{6}$ and the trend is now to use a CRP $>10 \mathrm{mg} / \mathrm{l}$ in conjunction with the CDAI. Remission (see below) is widely accepted as a CDAI $<150$ and response is increasingly defined as a decrease in CDAI $\geqslant 100$ points. It would make sense to define disease activity in groups of 100 points, at least until a sensitive, responsive, and validated index superior to the CDAI is developed. ${ }^{7}$ This is an inconsistency that needs to be resolved, but until it can be modelled on clinical trial datasets disease activity is generally graded as in table 1.2.

\subsubsection{Remission}

The criterion used in most clinical trials when selecting CD patients in clinical remission is a CDAI $<150{ }^{8}$ This has become the customary definition and is accepted for the purposes of evaluating the literature and clinical trials for as long as the CDAI remains the principal index for evaluating outcome in trials of CD. In several studies, a biological index of Brignola $<100 .{ }^{9}{ }^{10}$ was also a requirement. This has the advantage of objectivity, but is not used in clinical practice. In keeping with the views of the International Organisation for the study of Inflammatory Bowel Disease, ECCO believes that studies evaluating the maintenance of remission in $\mathrm{CD}$ should last at least 12 months. $^{8}$

Table 1.1 Levels of evidence and grades of recommendation based on the Oxford Centre for Evidence Based Medicine

\begin{tabular}{|c|c|c|}
\hline Level & Individual study & Technique \\
\hline la & $\begin{array}{l}\text { Systematic review (SR) with homogeneity of level } 1 \\
\text { diagnostic studies }\end{array}$ & Systematic review (SR) with homogeneity of randomised controlled trials (RCTs) \\
\hline $1 \mathrm{~b}$ & Validating cohort study with good reference standards & Individual RCT (with narrow confidence interval) \\
\hline 1c & $\begin{array}{l}\text { Specificity is so high that a positive result rules in the } \\
\text { diagnosis ("SpPin") or sensitivity is so high that a negative } \\
\text { result rules } \\
\text { out the diagnosis ("SnNout") }\end{array}$ & All or none \\
\hline $2 a$ & SR with homogeneity of level $>2$ diagnostic studies & SR (with homogeneity) of cohort studies \\
\hline $\begin{array}{l}2 b \\
2 c\end{array}$ & Exploratory cohort study with good reference standards & $\begin{array}{l}\text { Individual cohort study (including low quality RCT; for example, }<80 \% \text { followup) } \\
\text { "Outcomes" research; ecological studies }\end{array}$ \\
\hline $3 a$ & SR with homogeneity of $3 \mathrm{~b}$ and better studies & SR with homogeneity of case-control studies \\
\hline $3 b$ & $\begin{array}{l}\text { Non-consecutive study; or without consistently applied } \\
\text { reference standards }\end{array}$ & Individual case-control study \\
\hline 4 & $\begin{array}{l}\text { Case-control study, poor or non-independent reference } \\
\text { standard }\end{array}$ & Case series (and poor quality cohort and case-control studies ) \\
\hline 5 & $\begin{array}{l}\text { Expert opinion without explicit critical appraisal, or based } \\
\text { on physiology, bench research, or "first principles" }\end{array}$ & $\begin{array}{l}\text { Expert opinion without explicit critical appraisal, or based on physiology, bench } \\
\text { research, or "first principles" }\end{array}$ \\
\hline \multicolumn{3}{|c|}{ Grades of recommendation } \\
\hline A & \multicolumn{2}{|c|}{ consistent level 1 studies } \\
\hline B & \multirow{2}{*}{\multicolumn{2}{|c|}{$\begin{array}{l}\text { consistent level } 2 \text { or } 3 \text { studies or extrapolations from level } 1 \text { studies } \\
\text { level } 4 \text { studies or extrapolations from level } 2 \text { or } 3 \text { studies }\end{array}$}} \\
\hline C & & \\
\hline D & \multicolumn{2}{|c|}{ level 5 evidence or troublingly inconsistent or inconclusive studies of any level } \\
\hline
\end{tabular}

Table 1.2 Grading of disease activity in Crohn's disease

\begin{tabular}{|c|c|c|}
\hline Mild & Moderate & Severe \\
\hline $\begin{array}{l}\text { Equivalent to a CDAl of } 150-220 \\
\text { For example, ambulatory, eating and drinking, } \\
<10 \% \text { weight loss. No features of obstruction, fever, } \\
\text { dehydration, abdominal mass, or tenderness. CRP } \\
\text { usually increased above the upper limit of normal }\end{array}$ & $\begin{array}{l}\text { Equivalent to a CDAl of } 220-450 \\
\text { For example, intermittent vomiting, or weight loss } \\
>10 \% \text {. Treatment for mild disease ineffective, or } \\
\text { tender mass. No overt obstruction. CRP raised } \\
\text { above the upperlimit of normal. }\end{array}$ & $\begin{array}{l}\text { Equivalent to a CDAl of }>450 \\
\text { For example, cachexia (BMI }<18 \mathrm{~kg}^{-2} \text { ), or } \\
\text { evidence of obstruction or abscess. Persistent } \\
\text { symptoms despite intensive treatment. CRP } \\
\text { increased. }\end{array}$ \\
\hline
\end{tabular}




\subsubsection{Response}

Response should be defined by a $\triangle \mathrm{CDAI} \geqslant-100$ points, although in some studies, including those initially evaluating the effectiveness of infliximab, a lesser end point of response with a reduction in CDAI $\geqslant 70$ points $^{11}{ }^{12}$ was used.

\subsubsection{Relapse}

The term relapse is used to define a flare of symptoms in a patient with established CD who is in clinical remission, either spontaneously or after medical treatment. Relapse is preferably confirmed by laboratory parameters, imaging, or endoscopy in clinical practice. For the purposes of clinical trials a CDAI $>150$ with an increase of more than 70 points has been proposed. ${ }^{8}$ However, if a therapeutic response is defined as a decrease in CDAI $\geqslant 100$ points, then the definition would more rationally be a CDAI $>150$ with an increase of 100 points from baseline. There is no international agreement on this, but future trials on $C D$ should take this into account. Other definitions (including CDAI $>150$, or a CDAI $>250$, or an increase of 50 points if the baseline was between 150 and 250) are considered less acceptable.

\subsubsection{Early relapse}

An arbitrary, but clinically relevant period of $<3$ months after achieving remission on previous therapy defines early relapse. The therapeutic significance needs to be defined.

\subsubsection{Pattern of relapse}

Relapse may be infrequent ( $\leqslant 1$ /year), frequent ( $\geqslant 2$ relapses/ year), or continuous (persistent symptoms of active CD without a period of remission). Although the terms are arbitrary, they are considered clinically relevant. The prognostic significance needs to be determined.

The term "chronic active disease" has been used in the past to define a patient who is dependent on, refractory to, or intolerant of corticosteroids, or who has disease activity despite immunomodulators. As this term is ambiguous it is best avoided. Instead, arbitrary, but more precise definitions, are preferred, including corticosteroid refractory or corticosteroid dependence.

\subsubsection{Corticosteroid refractory disease}

Patients who have active disease despite prednisolone up to $0.75 \mathrm{mg} / \mathrm{kg} / \mathrm{day}$ over a period of four weeks.

\subsubsection{Corticosteroid dependent disease}

Patients who are either

(a) unable to reduce corticosteroids below the equivalent of prednisolone $10 \mathrm{mg} /$ day (or budesonide below $3 \mathrm{mg}$ / day) within three months of starting corticosteroids, without recurrent active disease, or

(b) who have a relapse within three months of stopping corticosteroids.

The assessment of corticosteroid refractoriness or dependence should be made after careful exclusion of disease specific complications.

This definition of corticosteroid dependence requires that the total duration of corticosteroids does not exceed three months before a threshold equivalent to prednisolone $10 \mathrm{mg} /$ day is reached. Patients are still considered corticosteroid dependent if they relapse within three months of stopping corticosteroids. Although these limits are arbitrary, they serve as guidance for clinical practice and may be used for uniformity in clinical trials. The aim should be to withdraw corticosteroids completely.

\subsubsection{Recurrence}

The term recurrence is best used to define the reappearance of lesions after surgical resection (while relapse refers to the reappearance of symptoms, above).

\subsubsection{Morphological recurrence}

The appearance of new CD lesions after complete resection of macroscopic disease, usually in the neo-terminal ileum and/ or at the anastomosis, detected by endoscopy, radiology, or surgery..$^{13}{ }^{14}$ Endoscopic recurrence is currently evaluated and graded according to the criteria of Rutgeerts et al (0: no lesions; 1: less than five aphthous lesions; 2 : more than five aphthous lesions with normal mucosa between the lesions, or skip areas of larger lesions, or lesions confined to the ileocolonic anastomotic lining $(<1 \mathrm{~cm})$; 3: diffuse aphthous ileitis with diffusely inflamed mucosa; 4: diffuse ileal inflammation with larger ulcers, nodules, or narrowing. Hyperaemia and oedema alone are not considered as signs of recurrence). ${ }^{13}$

\subsubsection{Clinical recurrence}

The appearance of CD symptoms after complete resection of macroscopic disease, provided (for the purposes of clinical trials) that recurrence of lesions is confirmed. ${ }^{14}$

\subsubsection{Localised disease}

Intestinal $\mathrm{CD}$ affecting $<30 \mathrm{~cm}$ in extent. This usually applies to an ileocaecal location ( $<30 \mathrm{~cm}$ ileum \pm right colon), but could apply to isolated colonic disease, or conceivably to proximal small intestinal disease.

\subsubsection{Extensive Crohn's disease}

Intestinal Crohn's disease affecting $>100 \mathrm{~cm}$ in extent whatever the location. This applies to the sum of inflammation in discontinuous segments. While there is clearly a "grey area" of disease extent (between 30 and $100 \mathrm{~cm}$ ) and the length is arbitrary, this definition of extensive disease recognises the greater inflammatory burden and implications for medical and surgical decision making with this extent of disease.

\subsubsection{New patient}

A patient with active $C D$ presenting at, or shortly after diagnosis, with no previous therapy for $\mathrm{CD}$.

\subsubsection{Alternative therapy}

One that is used in place of conventional medicine.

\subsubsection{Complementary therapies}

Similar treatments used alongside conventional medicine (see section on alternative therapies for comment).

\subsubsection{Expert opinion}

The term "expert" is used here to refer to the opinion of the specialists in IBD representing multiple disciplines from 22 European countries who contributed to the ECCO Consensus. In some sections opinions from individual members of other expert bodies were obtained, including members of the European Society of Pathology (ESP) working group on Digestive Diseases, or European Society of Gastrointestinal and Abdominal Radiology (ESGAR).

\subsection{CLINICAL DIAGNOSIS AND IMAGING}

CD most frequently presents in late adolescence or early adulthood and is equally distributed between the sexes. ${ }^{15}$ Symptoms at presentation vary depending on the location, behaviour, and severity of disease, as well as extraintestinal manifestations and medication. The aim is to establish the diagnosis, and distribution of disease by appropriate techniques, as this influences the choice of treatment. The guidance on imaging reflects a gastroenterological perception on 
appropriate radiological techniques for patients with CD. Although the European Society of Gastrointestinal and Abdominal Radiology (ESGAR) was not officially involved in the working party, the chairman (W Reinisch) consulted frequently with $C$ Bartram, a founding member of ESGAR, during the process of guideline preparation.

\subsection{Clinical features of $C D$}

\section{ECCO statement 2A}

Symptoms of CD are heterogeneous, but commonly include diarrhoea for more than six weeks, abdominal pain, and/or weight loss. These symptoms should raise the suspicion of $C D$, especially in patients at young age. Systemic symptoms of malaise, anorexia, or fever are common [EL5, RG D]

Chronic diarrhoea is the most common presenting symptom; ${ }^{16}{ }^{17}$ a definition of a decrease in faecal consistency for more than six weeks may be adequate to differentiate this from, self limited infectious diarrhoea. ${ }^{17}{ }^{18}$ Abdominal pain and weight loss are seen in about $70 \%$ and $60 \%$ respectively of patients before diagnosis. Blood and/or mucus in the stool may be seen in up to $40 \%$ to $50 \%$ of patients with Crohn's colitis, but less frequently than in ulcerative colitis (UC). ${ }^{17}$ Abnormalities of the musculoskeletal system are the most common extraintestinal manifestations of IBD, encompassing peripheral and axial joints. ${ }^{19}$ Extraintestinal manifestations are most common when $\mathrm{CD}$ affects the colon (see section 12). Perianal fistulas are present in $10 \%$ of patients at the time of diagnosis ${ }^{20}$ (see section 9).

\subsection{Diagnosis}

\section{ECCO statement 2B}

A single gold standard for the diagnosis of $C D$ is not available. The diagnosis is confirmed by clinical evaluation and a combination of endoscopic, histological, radiological, and/or biochemical investigations [EL5, RG D]

$\mathrm{CD}$ is a heterogeneous entity comprising a variety of complex phenotypes. ${ }^{19} 2122$ Originally, Dr Burrill Crohn and colleagues described regional ileitis as a chronic inflammatory disease restricted to the terminal ileum in association with intestinal stenoses or fistulas, but not crossing the ileocaecal valve. ${ }^{23}$ The original concept has subsequently extended potentially to affect the entire gastrointestinal tract. ${ }^{24-26}$ As there is no single way to diagnose CD, Lennard-Jones et al have defined macroscopic and microscopic criteria to establish the diagnosis. The macroscopic features include physical examination, endoscopy, radiology, and examination of an operative specimen. Microscopic features can be only partly assessed on mucosal biopsy, but completely assessed on an operative specimen. The diagnosis depends on the finding of discontinuous and often granulomatous intestinal inflammation. ${ }^{17}$ The current view is that the diagnosis is established by a nonstrictly defined combination of clinical presentation, endoscopic appearance, radiology, histology, surgical findings and, more recently, serology. This still results in diagnostic obstacles. A change in diagnosis to UC during the first year occurs in about $10 \%-15 \%$ of cases. IBD restricted to the colon that cannot be allocated to CD or UC categories is best termed colitis unclassified and the term indeterminate colitis confined to operative specimens as originally described. ${ }^{27}$ The indiscriminate use of the term indeterminate colitis to cover all cases of diagnostic uncertainty is confusing in the literature and imprecise in practice.

\subsubsection{History and examination}

\section{ECCO statement $2 \mathrm{C}$}

A full history should include detailed questioning about the onset of symptoms, recent travel, food intolerances, contact with enteric illnesses, medication (including antibiotics and non-steroidal anti-inflammatory drugs), smoking, family history, and history of appendicectomy [EL5, RG D]

\section{ECCO statement 2D}

Careful questioning about nocturnal symptoms, features of extraintestinal manifestations involving the mouth, skin, eye, or joints, episodes of perianal abscess, or anal fissure is appropriate. General examination includes general wellbeing, pulse rate, blood pressure, temperature, abdominal tenderness or distension, palpable masses, perineal and oral inspection, and rectal digital examination. Measurement of body weight and calculation of body mass index are recommended [EL5, RG D]

Smoking, prior appendicectomy, and a family history of IBD have been reproduced as risk factors for the onset of CD. ${ }^{28}{ }^{29}$ Retrospective studies on non-steroidal anti-inflammatory drugs as a risk factor for $\mathrm{CD}$ are less consistent. ${ }^{30}$

\subsubsection{Initial laboratory investigations}

\section{ECCO statement $2 E$}

Check for signs of acute and/or chronic inflammatory response, anaemia, fluid depletion, and signs of malnutrition/malabsorption [EL5, RG D]. Initial laboratory investigations should include CRP [EL2, RG B], and full blood count $[E L 5, R G D]$. If $C$ reactive protein is not available, then measurement of the erythrocyte sedimentation rate (ESR) is recommended [EL5, RG D]. Microbiological testing for infectious diarrhoea including Clostridium difficile toxin is recommended [EL2, RG B]. Additional stool tests may be needed for patients who have travelled abroad. In a patient with a history consistent with $C D$, additional clinical and laboratory investigations are not necessary [EL5, RG D]

Anaemia and thrombocytosis represent the most common changes in the full blood count in patients with $\mathrm{CD}$. The $\mathrm{C}$ reactive protein (CRP) and erythrocyte sedimentation rate (ESR) are standard laboratory surrogates of the acute phase response to inflammation. The CRP broadly correlates with disease activity of $\mathrm{CD}$ assessed by standard indices and indicates serial changes in inflammatory activity because of its short half life of 19 hours. ${ }^{31-36}$ The ESR less accurately measures intestinal inflammation in $\mathrm{CD}$ by reflecting changes of plasma protein concentration and packed cell volume. The ESR increases with disease activity, but correlates better with colonic rather than ileal disease. ${ }^{37}$ Neither of these parameters is specific enough to permit 
differentiation from UC or enteric infection. Evidence for a pathophysiological role of certain strains of luminal bacteria in genetically susceptible hosts in CD comes from animal models and studies on innate immunity. None yet have a diagnostic role. The value of routine stool examination in patients with suspected CD or exacerbations of disease arises from both the differential diagnosis and high concordance with enteric infections such as $C$ difficile. ${ }^{38}$

\subsubsection{Procedures recommended to establish the diagnosis}

\section{ECCO statement $2 \mathrm{~F}$}

For suspected $C D$, ileocolonoscopy and biopsies from the terminal ileum as well as each colonic segment to look for microscopic evidence of $C D$ are first line procedures to establish the diagnosis [ELIb, RG A]

Colonoscopy with multiple biopsy specimens is well established as the first line procedure for diagnosing colitis. ${ }^{39-41}$ Ileoscopy with biopsy can be achieved with practice in at least $85 \%$ of colonoscopies and increases the diagnostic yield of CD in patients presenting with symptoms of IBD. ${ }^{39} 4042$ The most useful endoscopic features of CD are discontinuous involvement, anal lesions and cobble stoning. Colonoscopy predicts the anatomical severity of CD colitis with a high probability. ${ }^{43}$ Anatomical criteria of severity are defined as deep ulcerations eroding the muscle layer, or mucosal detachments or ulcerations limited to the submucosa but extending to more than one third of a defined colonic segment (right, transverse, left colon). ${ }^{43}$ When there is severe, active disease, the value of full colonoscopy is limited by a higher risk of bowel perforation ${ }^{41}$ and diagnostic errors are more frequent. In these circumstances initial flexible sigmoidoscopy is safer and ileocolonoscopy postponed until the clinical condition improves. ${ }^{2}$ The scoring of endoscopic disease activity in CD is reserved for clinical studies. ${ }^{8}$ Ileoscopy is superior for the diagnosis of $\mathrm{CD}$ of the terminal ileum ${ }^{44-46}$ when compared with small bowel radiology, whether performed as follow through (SBFT), intubation (small bowel enema (SBE), enteroclysis), or meal with pneumocolon (SBMP). Enteroscopy with biopsy by a push endoscope is safe and useful procedure for diagnosis of CD in selected patients with suggestive symptoms after failure of conventional radiology. ${ }^{47}$ The accuracy of capsule enteroscopy remains to be defined (below).

A plain abdominal radiograph is valuable in the initial assessment of patients with suspected severe CD by providing evidence of small bowel or colonic dilatation, calcified calculi, sacroiliitis, or the impression of a mass in the right iliac fossa. It is not a diagnostic test for CD.

\subsection{Extent of disease}

2.3. 1 Procedures recommended for establishing the extent of $C D$

\section{ECCO statement 2 G}

In a patient with evidence of CD determined by ileocolonoscopy, further investigations are recommended to examine the location and extent of CD in the small bowel irrespective of the endoscopic and histological findings in the terminal ileum [ELIb, RG A]

CD may affect the ileum out of reach of an endoscope, or involve more proximal small bowel (10\% of patients.)
Endoscopy and radiology are complementary techniques to define the site and extent of disease, so that optimal therapy can be planned. ${ }^{46} 48$

\section{ECCO statement $2 \mathrm{H}$}

Several techniques are used to investigate the small intestine including small bowel follow through, small bowel enema, transabdominal ultrasound, computed tomography (CT)enteroclysis (-graphy), and magnetic resonance imaging (MRI)-enteroclysis (-graphy). For determination of extent and location of small bowel $C D$, most centres will perform either a $\mathrm{SBE}$ or SBFT, with only some units undertaking CT- or MRIenteroclysis (-graphy)

Fluoroscopic examinations (SBFT, SBE) are the current standard for assessing the small intestine. These are ubiquitously available and permit a detailed analysis of the extent of diseased mucosal surface. Results of barium studies are, however, strongly influenced by the quality of the examination. Views may be obscured by overlying bowel loops, while recognition of aphthoid ulceration requires good compression. Cross sectional imaging (such as CT) provides additional information on bowel wall thickening, associated changes in vascularity and in the adjacent mesentery, which become more important as the severity of disease increases. The radiation burden from fluoroscopy and CT is appreciable, so alternatives such as ultrasound (US) or MRI should be considered where possible.

Radiographic techniques for imaging the small intestine may be divided into intubation (enteroclysis, CT- enteroclysis and MRI-enteroclysis) and non-intubation studies. Nonintubation examinations include SBFT and oral preparations for MR- or CT-enterography. ${ }^{49}{ }^{50}$ Disagreement persists regarding the optimum fluoroscopic technique for small bowel CD. Placement of a nasojejunal tube is onerous for patients and may result in additional radiation exposure, but the inherent problem of non-intubation strategies is a diminished ability to ensure even distension of the small bowel for accurate assessment of strictures. However, strictures may only be detectable by opacification with distension. Therefore, SBE has been considered the optimum investigation for CD, with a sensitivity of $93 \%$ and a specificity of $92 \%$ to exclude small bowel disease. ${ }^{51-53}$ In routine practice SBFT is simpler and may be preferred; it was superior to SBE for detecting mucosal disease, fistulas, or gastroduodenal involvement in a comparative study in $\mathrm{CD},{ }^{5455}$ but is operator dependent and not as good for strictures. The debate is unlikely to be resolved by wireless capsule enteroscopy or other techniques in the near future.

US is not good at identifying the extent of CD, but its nonionising character make it suitable for the initial evaluation of a young population, especially for ileal CD. The sensitivity for US is $87 \%-95 \%$ when performed by specialists, which is somewhat less than barium studies, ${ }^{56-60}$ but is even more operator dependent. It misses lesions predominantly in the upper GI tract or rectosigmoid. The role of colour, power Doppler and contrast enhanced power Doppler investigation of the bowel wall for defining disease activity remains to be determined.

Intestinal imaging with helical CT-enteroclysis or CTenterography has improved appreciably, leading to reports that it is complementary or even superior to barium studies for the detection of involved segments. ${ }^{61}{ }^{62}$ MRI has also undergone technical developments that may yet make it the 
method of choice complementary to ileocolonoscopy and biopsy for assessing location, extent, and disease activity. Its ability to detect extramural complications (abscess, fistula, sacroiliitis, gall stones, renal calculi) is an added advantage. However, magnetic resonance enteroclysis (MRE) is currently more invasive than SBE, as it involves intravenous, oral and rectal contrast, as well as intravenous antiperistaltic agents. Superior sensitivity and specificity by MRE (95\% and 93\%) compared with SBE (85\% and $77 \%$ ) has been claimed for the primary diagnosis of $\mathrm{CD}^{6}{ }^{63} \mathrm{MRE}$ can provide useful information about the activity of disease..$^{64} 65$

Leucocyte scintigraphy is safe, non-invasive, and potentially permits assessment of the presence, extent, and activity of inflammation patients who are not taking corticosteroids, but it lacks specificity. ${ }^{66}$

It is premature to recommend any single procedure for imaging of the small bowel. However, the very variety of techniques make it most desirable that clinicians discuss imaging with an appropriate radiologist, so that results can be reviewed in the context of the clinical history. ${ }^{267}$

\subsubsection{Procedures recommended for establishing the extent of stricturing $C D$}

\section{ECCO statement 2I}

Intestinal stenosis is defined by symptoms of obstruction, bowel lumen narrowing, and/or pre-stenotic dilatation. The significance of the extent of luminal narrowing is not clearly defined [EL5, RG D]

The procedures above (section 2.3.1) apply to stricturing disease, but obstructive symptoms create their own challenge. The most reliable criterion for defining a stricture is a localised, comparatively short persistent narrowing, whose functional effects may be judged from pre-stenotic dilatation. ${ }^{68}$

\section{ECCO statement $2 \mathrm{~J}$}

When endoscopic intubation of the intestine is not possible, radiological studies are necessary to determine disease extent and location [ELla, RG A]. Small bowel enema for small bowel disease and double contrast barium enema for large bowel disease are recommended [ELlc, RG A]. Complementary imaging procedures may be performed, including US, CT, and/or MRI [ELla, RG A]. Differentiation between inflammatory and fibrostenotic bowel stenosis would be very helpful, but current techniques do not permit an accurate distinction

Plain film radiography and CT have similar accuracy in identifying small bowel obstruction. Plain film radiography remains the initial method, but the ability to depict the cause of obstruction makes CT an important additional diagnostic tool. ${ }^{69}$

When small bowel stenosis is suspected an enteroclysis examination best distends the bowel to reveal extent and number of strictures. Based on availability, SBE is recommended as investigation of first choice, but MRI-enteroclysis is comparable. ${ }^{70}$ The functional significance of a stricture is best illustrated by pre-stenotic dilatation, but it is difficult to determine the full significance of any narrowing even with intubation studies. Reflux of gas or smooth muscle relaxants can distend narrowed loops. Enteroclysis most reliably differentiates irreversible stenosis from functional spasm. US is helpful in detecting pre-stenotic dilatation in small bowel strictures in severe cases that are candidates for surgery. ${ }^{71}$

If colonoscopy is incomplete because of stricture, then double, or even single contrast barium enema are usually procedures of first choice. ${ }^{72}$ CT colonography (CTC) can show the mucosal pattern and show colitis proximal to a stricture, but may not identify all strictures seen on colonoscopy. ${ }^{73-75}$

Differentiation between inflammatory and fibrostenotic strictures is crucial to the choice of therapy, but current techniques are insufficiently accurate. Disease activity at a stricture is inferred from by the presence or absence of ulceration that indicates active inflammation. Contrast enhanced Doppler US may be valuable in determining disease activity within strictures. ${ }^{76-78}$ Both CT and MRI illustrate mural changes with disease activity, but MRI is more sensitive. ${ }^{65} 7980$

\subsubsection{Procedures recommended for detecting extramural complications}

\section{ECCO statement $2 \mathrm{~K}$}

When an extramural complication is suspected, including fistula or abscess, US, CT, and/or MRI are appropriate investigations [ELlc, RG A]

US is an operator dependent, but readily available, diagnostic tool for the diagnosis of extramural complications in CD. For the detection of fistulas and abscesses, respective sensitivities of $87 \%$ and $100 \%$ have been reported. ${ }^{81}$

CT and MRI are highly accurate in complicated CD, especially for the detection of fistulas, abscesses, and phlegmons. ${ }^{82} 83$ The important advantages of MRI compared with CT include superior tissue contrast, absence of radiation exposure, capability of selecting cross sectional planes (transverse, coronal, sagittal), and higher sensitivity for intestinal and extraintestinal changes in CD. ${ }^{79}$ Surgically compared sensitivities for the detection of fistulas and abscesses of $83 \%$ and $100 \%$ respectively, have been reported for MRI. ${ }^{84}$ MRI enteroclysis is good and probably better than $U^{85}$ for detecting extramural complications of CD, but fluoroscopic studies are poor value. ${ }^{63}$ Laparoscopy may be necessary in selected patients, especially when the differential diagnosis of intestinal tuberculosis is being considered.

\subsubsection{Role of gastroduodenoscopy and biopsy in a patient with $C D$}

\section{ECCO statement $2 L$}

In routine practice gastroduodenoscopy is only recommended in patients with upper gastrointestinal symptoms [EL5, RG D]

CD involving the upper gastrointestinal tract is almost invariably accompanied by small or large bowel involvement. ${ }^{86-88}$ Gastric biopsies may be useful when a patient has colitis unclassified, as focal active gastritis in the absence of ulceration may be a feature of CD (section 3.2.5). 
2.3.5 Role of wireless capsule endoscopy (WCE) in
suspected or proven CD

\section{ECCO statement $2 \mathrm{M}$}

Wireless capsule endoscopy (WCE) represents an advance for small bowel imaging, but large prospective studies are needed to confirm the diagnostic relevance in CD. WCE may be considered in symptomatic patients with suspected small bowel $C D$ in whom a stricture/stenosis has been excluded, endoscopy of terminal ileum is normal or not possible, in whom fluoroscopic or cross sectional imaging have not showed lesions [EL2, RG B]

WCE is a novel method of directly visualising small bowel lesions in patients with IBD that may be missed by traditional endoscopic or radiological procedures. Initial studies suggest that WCE is a superior and more sensitive procedure than SBFT and CT-enteroclysis in establishing the diagnosis and estimating the extent of $\mathrm{CD}^{89-92}$ However, $\mathrm{CD}$ associated lesions seen at WCE still need more precise definition, because specimens for histological evaluation are not obtained. Large prospective studies are needed to position WCE in a diagnostic algorithm for CD. Contraindications for WCE include gastrointestinal obstruction, strictures or fistulas, pacemakers or other implanted electromedical devices, and swallowing disorders. ${ }^{93}$

\subsubsection{Procedures recommended preoperatively}

\section{ECCO statement $2 \mathrm{~N}$}

Preoperative imaging should follow strategies used for the primary diagnosis of CD [EL5, RG D]

Small bowel mucosal lesions proximal to resection margins are found in about $65 \%$ of patients at the time of surgical intervention, most often undetected by radiography. These lesions do not, however, influence postoperative outcome. ${ }^{94} 95$

\subsection{THE HISTOLOGICAL DIAGNOSIS OF CD}

During the past 25 years, several elements have influenced the accuracy of the histological diagnosis of $\mathrm{CD}$. The widespread introduction of colonoscopy permitted the analysis of multiple mucosal biopsies from different segment of the colon and the ileum. The introduction of new therapies inducing healing of the mucosa has made the pathologist aware of the impact of treatment upon the diagnostic features.

For this section articles reporting original research into the reproducibility, sensitivity, or specificity of individual features for the histological diagnosis of CD were sought from the literature using Medline and Pubmed. As further selection criteria, only those features that achieved moderate reproducibility judged by $\kappa$ value, or findings that were confirmed by subsequent studies, were considered. The purpose is to propose consensus guidelines for the histological diagnosis of $\mathrm{CD}$. The aspects discussed include: procedures required for a proper diagnosis; features that can be used for the analysis of endoscopic biopsies; features that can be used for the analysis of surgical samples; and diagnostic criteria. Questions that are addressed include: how many features should be present for a firm diagnosis? is it useful to search for dysplasia? the role of histology in management? and which features if any, can be used for assessment of disease activity?

\subsection{Procedures for the diagnosis with endoscopic biopsies}

3.1.1 Number of biopsies

\section{ECCO statement $3 \mathrm{~A}$}

For a reliable diagnosis of CD "multiple" biopsies from five sites around the colon (including the rectum) and the ileum should be obtained. Multiple biopsies implies a minimum of two samples from each site [EL2, RG B]

\section{ECCO statement 3B}

In patients with fulminant colitis, two samples from at least one site should be obtained [EL5, RG D]

For the initial diagnosis, analysis of a full colonoscopic biopsy series, rather than a single rectal biopsy, produces the most reliable diagnosis of CD. ${ }^{96-103}$ Samples are preferably obtained both from areas that are involved by the disease and from uninvolved areas. During follow up examinations, a smaller number of biopsy samples may be useful to confirm the diagnosis. In post-surgical follow up, biopsies of the neoterminal ileum are indicated when disease recurrence is suspected. Where patients have undergone ileal pouch-anal anastomosis, biopsies of the afferent limb are indicated when $\mathrm{CD}$ is suspected. Multiple biopsies are indicated when the patient is investigated during screening for dysplasia (= intraepithelial neoplasia).

\subsubsection{Handling of biopsies}

\section{ECCO statement $3 \mathrm{C}$}

The biopsy samples should be accompanied by clinical information including the age of the patient, duration of disease, and duration and type of treatment [EL5, RG D]

\section{ECCO statement 3D}

All tissue samples should be fixed immediately by immersion in buffered formalin or an equivalent solution before transport [EL5, RG D]

\section{ECCO statement 3E}

As lesions may be mild or focal it is recommended that multiple sections from each sample are examined [EL2, RG B]

Biopsies from different regions should be handled in a way that the region of origin can be identified. This can be done by using different containers, multi-well cassettes,or an acetate strip. Orientation of the samples using filter paper 
(submucosal side down) before fixation, may yield better results, because it permits a better assessment of architectural abnormalities [EL5, RG D]. The ideal number of sections to be examined in routine practice is not established, but numbers vary between two and six in different studies. ${ }^{102} 103$ The diagnostic yield increases when more sections are examined. It is not clear whether serial sections or step sections from different levels of the sample should be examined. In one comparative study of rectal biopsies, serial sectioning increased the ability to detect focal abnormalities including granulomas compared with step sectioning. Confirmation of this finding is needed. ${ }^{104}$ In routine practice, step sections may be the simplest procedure. Obtaining two or three tissue levels has been proposed, each consisting of five or more sections. ${ }^{105}$ Routine staining with haematoxylin and eosin are appropriate for diagnosis. [EL5, RG D] At present special stains, immunohistochemistry, or other techniques for diagnostic purposes are not needed routinely.

This proposal is in agreement with guidelines proposed by the German, Austrian, and Swiss inflammatory bowel disease study groups and the British Society of Gastroenterology initiative. ${ }^{100}{ }^{106-110}$ The use of multiple biopsies from different sites is supported by the expert opinion of clinicians, except for patients presenting with fulminant colitis. Fifty eight per cent of the clinicians agree to take two samples from one or two regions in fulminant colitis. Eight per cent do not perform endoscopy in fulminant colitis and 34\% would take only one sample. The proposal to use multiple biopsies for the diagnosis of CD is supported by data from the literature. ${ }^{96} 97$ For fulminant colitis, there are no appropriate data available.

\subsection{Diagnostic features}

3.2.1 Combined microscopic features

\section{ECCO statement $3 F$}

Focal (discontinuous) chronic (lymphocytes and plasma cells) inflammation and patchy chronic inflammation, focal crypt irregularity (discontinuous crypt distortion), and granulomas (not related to crypt injury) are the generally accepted microscopic features that permit a diagnosis of CD [EL2, RG $B]$. The same features and, in addition, an irregular villous architecture, can be used for analysis of endoscopic biopsy samples from the ileum. If the ileitis is in continuity with colitis, the diagnostic value of this feature should be used with caution [EL2, RG B]

A large variety of microscopic features have been identified that help to establish a diagnosis of CD, and reported in the literature. They are summarised in table 3.1. The reproducibility of these features, as well as the sensitivity and specificity have been studied repeatedly (section 3.2.5).

\subsubsection{Focal or patchy inflammation}

Focal or patchy chronic inflammation means a variable increase in lamina propria cellularity across the biopsy specimen and not confined to the superficial zone. A focal increase implies a normal background cellularity with a localised increase in cells. Patchy increase means an abnormal background cellularity with variable intensity.

Table 3.1 Microscopic features used for the diagnosis of Crohn's disease

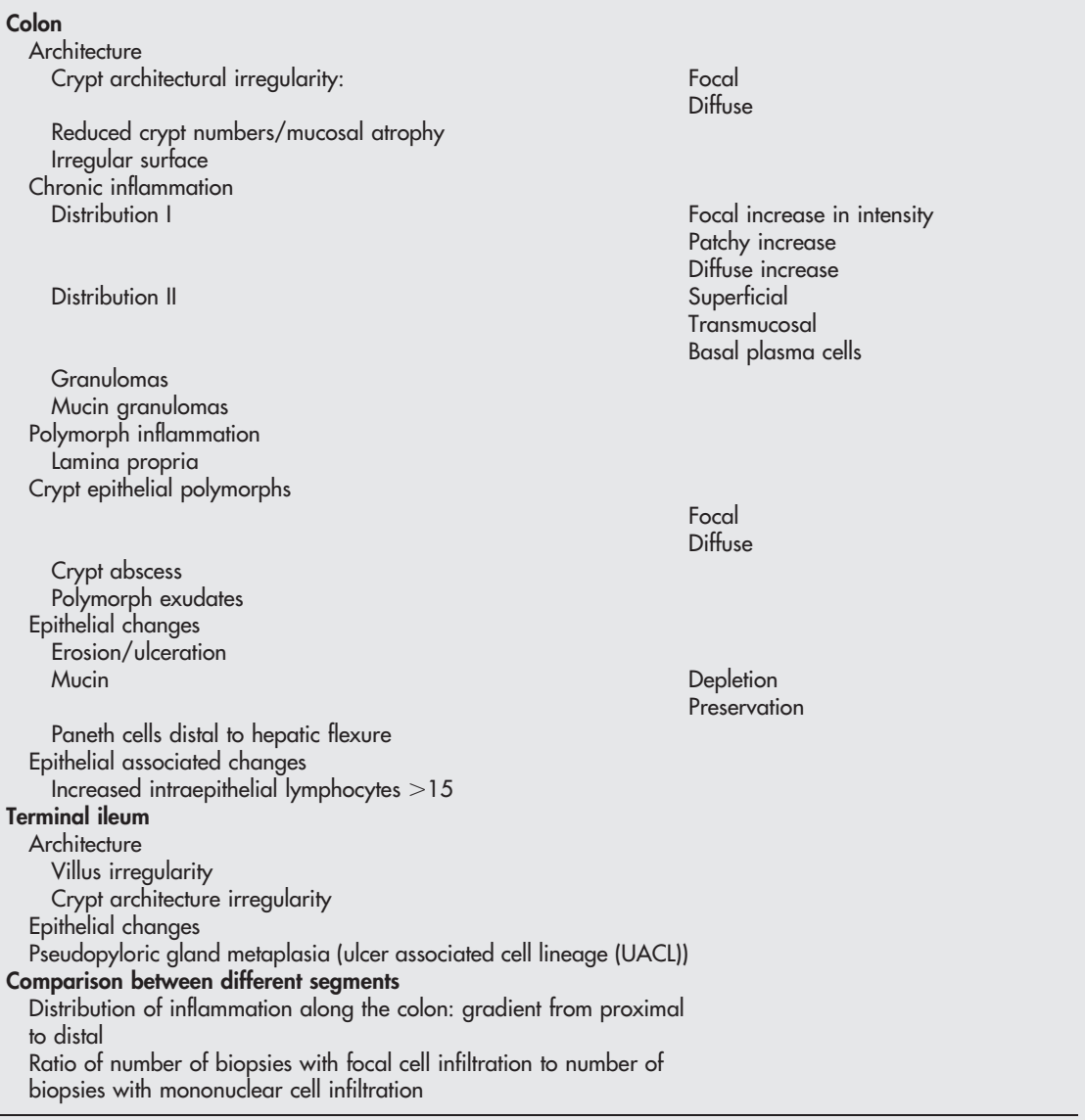


Focal or patchy increase should not be confused with the presence of normal lymphoid aggregates. Differences in cellularity between multiple biopsy specimens can be assessed with greater reproducibility than variation within a single specimen.

\subsubsection{Crypt irregularity}

Crypt irregularity implies crypt abnormalities in $>10 \%$ of the crypts when focal or patchy inflammation are present. Crypt irregularity can be either crypt distortion (non-parallel crypts, variable diameter, or cystically dilated crypts), crypt branching, and crypt shortening. ${ }^{100}$ The presence of more than two branched crypts in a well orientated biopsy specimen can be regarded as abnormal. ${ }^{100}$

\subsubsection{Granulomas}

The granuloma in CD is defined as a collection of epithelioid histiocytes (monocyte/macrophage cells), the outlines of which are often vaguely defined. Multinucleated giant cells are not characteristic and necrosis is usually not apparent. Only granulomas in the lamina propria not associated with active crypt injury may be regarded as a corroborating feature of CD. Granulomas associated with crypt injury are less reliable features. ${ }^{111}$ Non-caseating granulomas, small collections of epithelioid histiocytes, and giant cells, or isolated giant cells can be seen in infectious colitis (granulomas suggest Mycobacteriumsp, Chlamydiasp, Yersinia pseudotuberculosis, Treponema sp; microgranulomas suggest Salmonellasp, Campylobactersp, Yersinia enterocolitica; giant cells suggest Chlamydia $s p$ ) and must not be regarded as evidence for CD.

\subsubsection{Number of features needed for diagnosis}

The selection of these features is based upon a systematic literature review. They achieve a diagnostic sensitivity and specificity of at least $50 \%$ and a moderate to good reproducibility ( $\kappa$ of 0.4 or percentage agreement of at least $80 \%) .{ }^{103} 104112113$ They were presented to a panel of experts and scored according to the quality of the study and expert opinion. Focal crypt irregularity scored highest on the evidence of more than one valid study of adequate size and from expert opinion; focal or patchy chronic inflammation was validated by evidence from single paper and expert opinion. The features were also tested in a workshop, involving non-expert and expert pathologists and selected by $50 \%$ or more of the pathologists correctly identifying each case. $^{96}$ The patchy nature of the inflammation is only diagnostic in untreated adult patients. Inflammation can become patchy in UC under treatment, and young children (age $<10$ years) with UC may present with discontinuous inflammation. ${ }^{14-119}$

The presence of one single feature is not regarded as sufficient for a firm diagnosis. For single or multiple endoscopic samples there are no data available as to how many features must be present for a firm diagnosis of CD. For surgical material, it has been suggested that a diagnosis of CCD should be made when three features are present in the absence of granulomas, or when an epithelioid granuloma is present with one other feature provided that specific infections are excluded [EL5, RG D]. ${ }^{109}$ The same definition could be proposed for mucosal samples obtained during endoscopy. The following features can be identified in the mucosa and thus in endoscopic biopsy samples: granulomas and focal (segmental or discontinuous) crypt architectural abnormalities, in conjunction with focal or patchy chronic inflammation (chronic is defined as presence of lymphocytes and plasma cells), or mucin preservation at active sites. These are, therefore, potentially reliable markers for the diagnosis of CD.

Most expert clinicians (91\%) and all pathologists agree that the presence of a granuloma and at least one other feature establishes a diagnosis of CD. The second feature can be either inflammation (focal) or, preferably, architectural abnormalities. A pseudovillous appearance of the colorectal surface is more predictive of ulcerative colitis, while focal architectural abnormalities favour CD. However, finding a granuloma is not always necessary for a diagnosis of CD. Additional features that have been found to be useful are increased intraepithelial lymphocytes, ${ }^{96}$ transmucosal inflammation, ${ }^{112}$ focal chronic inflammation without crypt atrophy, focal cryptitis (although reproducibility is poor), ${ }^{100}{ }^{120}$ aphthoid ulcers, disproportionate submucosal inflammation, nerve fibre hyperplasia, ${ }^{121}$ and proximal location of ulceration and architectural distortion. When multiple biopsies are available, ileal involvement and a distribution of the inflammation showing a proximal to distal gradient can also be useful. The absence of features that are highly suggestive or diagnostic of ulcerative colitis, such as diffuse crypt irregularity; reduced crypt numbers and general crypt epithelial polymorphs, can also orient towards a diagnosis of $\mathrm{CD}$.

In difficult cases, gastric biopsies might help establish the diagnosis of $\mathrm{CD}$ by the presence of granulomas or focally enhanced or focal active gastritis. The latter is characterised by the absence of Helicobacter pylori and the presence of a perifoveolar or periglandular cellular infiltrate composed of mononuclear cells $\left(\mathrm{CD}^{+} \mathrm{T}\right.$ cells and $\mathrm{CD}^{+} 8^{+}$cells) and granulocytes. Focal gastritis is not exclusive to CD [EL4, RG C]. ${ }^{122-126}$

\subsection{Histology and dysplasia-intraepithelial neoplasia} 3.3.1 Number of biopsies

\section{ECCO statement $3 G$}

The microscopic features for the diagnosis and grading of dysplasia-intraepithelial neoplasia of the colon in Crohn's disease are the same as those proposed for ulcerative colitis and, similarly, a second opinion is recommended for a firm diagnosis [EL2, RG B]

\section{ECCO statement $3 \mathrm{H}$}

As for ulcerative colitis, sporadic adenomas may be difficult to distinguish from dysplasia associated lesions or masses. The distinction is however important, because the management of sporadic adenomas differs from that of colitis associated dysplasia. The patient's age, the site, and morphology of the lesion, along with biopsies of flat surrounding mucosal, may be helpful in this distinction [EL2, RG B]

Patients with extensive Crohn's colitis carry an increased risk of colorectal cancer. Endoscopy with biopsy can be used for secondary prevention and the detection of dysplasia (intraepithelial neoplasia) in UC [EL2, RG C]. The optimal number of biopsies required for a reliable diagnosis of intraepithelial neoplasia has not been established. It has been proposed that 6 to 10 samples from different sites in the colon should be obtained, as suggested for UC. The current recommendation is to biopsy the colon at $10 \mathrm{~cm}$ intervals. Biopsies are labelled separately so that the segment of colon from which the tissue is obtained can be subsequently identified. It has been estimated that 33 biopsy specimens are required to give $90 \%$ confidence in the detection of dysplasia if it is indeed present. ${ }^{127}$ These studies on UC have not been replicated in Crohn's colitis. The focal nature of inflammation in Crohn's colitis, the possibility of strictures and prevalence of 
segmental resection means that surveillance practice in UC cannot be transferred directly to Crohn's colitis. The purpose of this section is not designed to make surveillance recommendations, but to acknowledge that if it is performed then the number of biopsies necessary to detect dysplasia is large. The use of targeted biopsies, aimed at lesions identified by chromoendoscopy or endomicroscopy, may change the policy of taking biopsies in the future.

\subsubsection{Microscopic features}

Microscopic features that are used for a diagnosis of intraepithelial neoplasia include architectural and cytological abnormalities. Architectural abnormalities are crowding of glands, thickening of the mucosa, lengthening and distortion of the crypts with excessive budding, and increased size. Surface and crypts are lined by tall, high columnar cells in which there is some mucus differentiation. Mucin tends to be in columnar cells rather than in the usual goblet cells. Nuclear changes are morphologically similar to those seen in tubular adenomas: hyperchromatic and enlarged nuclei, with nuclear crowding and frequent overlapping. The nuclei are also typically stratified. Mitotic figures may be present in the upper part of the crypt, and even in the surface (which is abnormal). ${ }^{128} 129$

\subsubsection{Additional techniques}

The use of additional techniques (including flow cytometry, immunohistochemistry) and the search for markers (such as the expression of p53) can be helpful for solving diagnostic problems and to support the diagnosis of intraepithelial neoplasia. These techniques, however, identify changes that are not entirely the same as dysplastic changes, which represent a complex phenomenon. Therefore, and because of practical availability and costs, the simple morphological recognition of dysplasia remains important for the management of the cancer risk in CD.

\subsection{Surgery and pathology}

\section{ECCO statement 31}

A surgical sample needs a complete macroscopical examination, carried out in an orderly and systematic manner, including photographic documentation, preferably at the time when the specimen is removed [EL5, RG D]. Once macroscopical observations are completed, the sample is opened along its longitudinal axis (along the antimesenteric or antimesocolic border, except perhaps at the sites of any carcinoma, where it may be preferable to leave that small segment unopened during fixation) and specimens for microscopy are collected, including the lymph nodes, terminal ileum, and appendix [EL2, RG B]

\section{ECCO statement $3 \mathbf{J}$}

The optimum number of samples from a colectomy specimen that should be obtained has not been established. However, multiple samples will improve the diagnostic yield. It is a mistake to sample only visible lesions. The samples can be processed routinely [EL5, RG D]

When surgical samples are available, the macroscopic aspects of the condition and the transmural character of the disease can be identified and in general many more features can be used for diagnostic purposes. ${ }^{121} 130$ The features are summarised in boxes 3.2 and 3.3. Fat wrapping has a high predictive value for the diagnosis of $\mathrm{CD} .{ }^{131} 132$

Box 3.2 Macroscopic features for the diagnosis of Crohn's disease

- lleal disease*

- Rectum typically spared

- Confluent deep linear ulcers, aphthoid ulcers

- Deep fissures

- Fistulas

- Fat wrapping*

- Skip lesions (segmental disease)

- Cobblestoning

- Thickening of the intestinal wall*

- Strictures

*Typical discriminating features for a diagnosis of Crohn's disease compared with other conditions

Box 3.3 Microscopic features for the diagnosis of Crohn's disease in surgical specimens

- Transmural inflammation*

- Aggregated inflammatory pattern, transmural lymphoid hyperplasia*

- Submucosal thickening (expansion by fibrosis-fibromuscular obliteration and inflammation)

- Fissures

- Sarcoid granuloma (including in lymph nodes)*

- Abnormalities of the enteric nervous system (submucosal nerve fibre hyperplasia and ganglionitis)*

- Relatively unchanged epithelia-mucin preservation (goblet cells often normal)

*Typical discriminating features for a diagnosis of Crohn's disease compared with other conditions

\subsection{Histology and disease activity}

\section{ECCO statement $3 \mathrm{~K}$}

The pathology report should give an indication of the activity of the disease. Inactivity in the biopsy may not reflect inactivity in the patient [EL5, RG D]

Histological examination is routinely used for the diagnosis of UC and CD. The occurrence of healing of mucosal inflammation has already been noted as a feature of resolution in UC. Therefore, biopsies are used to discriminate between quiescent disease, inactive disease, and different grades of activity in UC. This has led to the introduction of scoring systems for the assessment of disease activity in UC and their use in clinical drug trials. ${ }^{127}$

In contrast with UC, disease activity is not generally assessed by pathologists for CD. This is mainly attributable to the discontinuous character of the disease, inducing sampling error, and the fact that the ileum may be the only area 
involved. Sampling error is very important, especially when only rectal biopsies are available. Microscopic analysis of multiple samples from different segments of the colon and ileum might provide useful information and permit assessment of disease activity. Arguments in favour come from other diseases such as UC and $H$ pylori related gastritis and from clinical drug trials. In UC, basal plasmacytosis can also help to predict relapse, while adequate control of the inflammation seems important for the prevention of the development of cancer, ${ }^{131-136}$ but neither have yet been studied in CD. The data available on histology and activity for CD are limited. Several clinical drug trials have shown that medical treatment can change the mucosal histology, promoting healing and normalisation of the mucosa. ${ }^{135-143}$ There is, however, no general agreement among expert clinicians about the use of microscopy to assess disease activity. If biopsies are used, then multiple samples have to be obtained and analysed. The presence of epithelial damage in association with neutrophils is a marker of disease activity. ${ }^{133}$ In CD a multivariate logistic regression model showed that severe lymphocytic (and eosinophilic) infiltration of the lamina propria, presence of crypt atrophy and absence of lymphocytic infiltration of the epithelium are the best variables for predicting uncomplicated disease. ${ }^{144}$

\subsection{CLASSIFICATION OF CROHN'S DISEASE}

Disease classification is an important step to provide appropriate tools that enable us to dissect differences in the features and behaviour of CD. Several ways of classifying CD have been used in the past. CD has been classified by disease phenotype (Rome or Vienna classification, modified in Montreal), by disease activity (mostly according to the CDAI), and by response to therapy (mainly corticosteroids: "corticosteroid resistant" or "corticosteroid dependent", above). Some disease causing mutations have been identified in the recent past, classification by genetic markers may be appropriate. Also immunological features such as ASCA or ANCA may look attractive for classifying the disease (immunotyping). The best classification of course would be by cause of disease, which is, however, still obscure.

\subsection{General recommendations}

\section{ECCO statement $4 \mathrm{~A}$}

No evidence based recommendation can be made to implement the routine clinical use of: genetic tests (for example, NOD2/CARD15, OCTN1 and 2, DLG5 or combinations); stool markers (for example, calprotectin, lactoferrin); serological markers (for example, ASCA, ANCA, ompC, 12, flagellin antibodies); intestinal permeability testing; or phenotype driven classifications

\section{ECCO statement 4B}

Serum levels of CRP are useful for assessing a patient's risk of relapse [EL2b, RG B]. High CRP levels are indicative of active disease [EL2a, RG B] or a bacterial complication [EL3, RG C]. CRP levels can be used to guide therapy and follow up [EL2a, RG B]

\subsection{Specific components}

4.2.1 Classification by genetic or other markers

Genetic tests are considered to represent any diagnostic test that permits the determination of a particular genetic constellation. In this capacity, genetic tests may be gene based, but may also comprise protein based tests of gene function. Other tests designed to discriminate or classify $C D$ include serological tests.

NOD2/CARD15 mutations have been clearly associated with susceptibility to CD [ELla]. ${ }^{145-147}$ They were further related to particular phenotypes (characterised by ileal and stricturing disease) [ELla]. ${ }^{148-153}$ The relative importance of NOD2 mutations differs between white populations and nonwhite populations (mostly no NOD2 mutations) but also within Europe. It is expected that further disease susceptibility genes will be detected soon [EL2b]. ${ }^{154}{ }^{155}$ Genetic tests are not yet implemented in clinical routine strategies because of low individual predictive value and because no preventive or therapeutic strategies based on the genetic findings exist to influence disease. Counselling should be done before any genetic test. Counselling should be performed using an interdisciplinary approach, including human genetics and disease specialists.

Serological tests (ASCA/ANCA) have a high specificity for the diagnosis of $\mathrm{CD}$ if the pattern is positive ( $\left.\mathrm{ASCA}^{+} / \mathrm{ANCA}^{-}\right)$ [EL2a]. The predictive value is too low for routine clinical use [EL2a]. ${ }^{156-161}$ Clinical permeability scores using inert macromolecules (such as lactulose, L-rhamnose, or mannitol) show abnormal values in a fraction of patients. They have some predictive value for relapse, but they are not available outside of specialised centres and are of no predictive value for individual patients [EL2a]. ${ }^{162} 163$

\subsubsection{Classification by phenotype}

The Vienna classification was introduced at the World Congresses of Gastroenterology in 1998 and provides the most recent international consensus on CD phenotype. ${ }^{68}$ Age at diagnosis (A), disease location (L), and disease behaviour (B) are the three categories for allocating patients. The A and L category seem to be stable during the course of disease, but the $\mathrm{B}$ category is not. ${ }^{164}$ Patient classification by phenotype has an impact on the choice of medication with regard to disease location and disease behaviour (see also section on therapy). The Vienna Classification is a first step towards standardising this process. At the World Congress of Gastroenterology in Montreal (2005) an update of the Vienna classification was proposed, ${ }^{165}$ which includes upper gastrointestinal and perianal modifiers for disease location and behaviour. The possibility of including genetic and serological markers in the classification was examined and the clinical reclassification is in the process of being validated.

\subsubsection{Classification by CRP or other indicators of inflammation}

Clinical disease activity is habitually determined by CDAI and separates patients with active disease from patients with quiescent disease. The CDAI is heavily weighted towards subjective symptom reports such as diarrhoea, abdominal pain, or general wellbeing. It does not necessarily reflect the inflammatory activity in the gut. Inflammation related markers are therefore detected from the serum or the stool. Therefore more reliable parameters including laboratory tests of inflammation would be useful.

Raised serum CRP is found in patients with endoscopically active CD and low levels of CRP identify patients in stable remission. The CRP in remission may help identify those at a higher risk of relapse [EL2b] (see also section 6.1.2). When 101 patients with CD were followed up prospectively for two years, half had a raised CRP that correlated well with clinical activity. About a third presented with active disease despite a normal CRP and a third had a raised CRP but clinically inactive disease. The likelihood of relapse after two years was 
higher for the patients with an increased CRP compared with those with a normal CRP. ${ }^{166}$ The GETAID group also prospectively followed up 71 CD patients with medically induced remission and measured laboratory markers (full blood count, CRP, ESR, $\alpha_{1}$ antitrypsin, orosomucoid) every six weeks. ${ }^{161}$ In total, 38 patients relapsed (defined as a CDAI $>150$ with an increase of $>100$ points from baseline) after a median of 31 weeks. Only two laboratory markers were predictive of relapse: CRP $(>20 \mathrm{mg} / \mathrm{l})$ and ESR (>15 mm lst h). Patients with both markers positive had an eightfold increased risk for relapse. The negative predictive value was $97 \%$, suggesting that negative results for both markers could almost certainly rule out relapse in the next six weeks. A further cohort study used biochemical markers to develop a predictive index of relapse. ${ }^{9}$ Forty one patients with clinical inactive disease $($ CDAI $<150)$ for six months were followed up using a range of biochemical markers of inflammation until relapse. ${ }^{9}$ A total of 17 of 41 patients relapsed. ESR, $\alpha_{2}$ globulin, and $\alpha_{1}$ glycoprotein were the best predictors to distinguish relapsers from nonrelapsers. The authors concluded that high values predicted relapse in the following one to two years. Very high CRP levels are indicative of bacterial complication (such as an abscess) [EL3]. A variety of other markers (orosomucoid, IL6, sIL2R, intestinal permeability ${ }^{9}{ }^{158}{ }^{163}$ ) may have similar capability.

Stool markers such as calprotectin, lactoferrin, or tumour necrosis factor are related to the extent of ulcerated intestinal surface and to the degree of inflammation These may have a high predictive value for the presence of ileocolonic inflammation and for upcoming clinical relapse..$^{156} 161164$ However, properly powered studies are needed to confirm their value in routine practice.

\section{ACKNOWLEDGEMENTS}

Funding was provided by the Robert Bosch Foundation (Stuttgart, Germany) a non-profit and non-pharmaceutical organisation. Additional support ECCO comes through annual subscriptions from member countries. Support from industry includes Abbott Laboratories, Giuliani SA, Ferring Pharmaceuticals, Protein Design Labs, Centocor, Schering Plough, Dr Falk Pharma, Shire, ELAN, and Given Imaging. Grateful thanks to all contributors, as well as to Mrs Ulrike Firley and Mrs Helen Small for secretarial support.

\section{Authors' affiliations}

E F Stange, Chefarzt, Abteilung für Innere Medizin 1 Schwerpunkte Gastroenterologie, Hepatologie und Endokrinologie, Robert Bosch

Krankenhaus, Stuttgart, Germany

S Travis, John Radcliffe Hospital, Oxford, UK

S Vermeire, University Hospital KULeuven, Leuven, Belgium

C Beglinger, Department of Gastroenterology, The University Hospital, Basle, Switzerland

L Kupcinkas, Kaunas University of Medicine hospital, Department of Gastroenterology, Kaunas, Lithuania

K Geboes, Department of Pathology, University Hospital KULeuven, Leuven, Belgium

A Barakauskiene, Clinic of Gastroenterology, Vilnius University Hospital, Vilnius, Lithuania

V Villanacci, Cattedra di Chirurgia Generale, Universita degli Studi di Brescia, UO1 Chirurgia Generale, Spedali Civili Brescia, Brescia, Italy

A Von Herbay, St Mark's Hospital, Harrow, Middlesex, UK

B F Warren, Department of Histopathology, John Raddliffe Hospital, Oxford, UK

C Gasche, Department of Internal Medicine IV, Division of Gastroenterology and Hepatology, Medical University of Vienna, Austria

H Tilg, University Hospital Innsbruck, Department of Medicine, Innsbruck, Austria

S W Schreiber, University Hospital Schleswig-Holstein UKSH, Department of General Internal Medicine, Kiel, Germany J Schölmerich, Department of Internal Medicine I, University of Regensburg, Germany
W Reinisch, Univ-Klinik Innere Medizin IV, Abt Gastroenterology and Hepatology, Vienna, Austria

Competing interests: the authors have variously received unrestricted educational grants, consultancy fees and/or hospitality from all pharmaceutical companies in the field of inflammatory bowel disease, but no author was paid for this work nor did any company contribute to the consensus statements or text.

\section{REFERENCES FOR DEFINITIONS AND DIAGNOSIS}

1 Shivananda S, Lennard-Jones J, Logan R, et al. Incidence of inflammatory bowel disease across Europe: is there a difference between the north and south? Results of the European collaborative study on inflammatory bowel disease (EC-IBD). Gut 1996;39:690-7

2 Carter MJ, Lobo AJ, Travis SP, et al. Guidelines for the management of inflammatory bowel disease in adults. Gut 2004;53(suppl 5):V1-16.

3 Stange EF, Schreiber S, Fölsch UR, et al. Diagnostik und Therapie des M. Crohn-Ergebnisse einer evidenzbasierten Konsensuskonferenz der Deutschen Gesellschaft für Verdauungs- und Stoffwechselkrankheiten. Z Gastroenterol 2003;41:19-68.

4 Fink A. Consensus methods: characteristics and guidelines for use. Am J Public Health 1984;74:979-83.

5 Centre for Evidence Based Medicine, Oxford. Levels of evidence and grades of recommendation. http://www.cebm.net/levels_of_evidence.asp.

6 Su C, Lichtenstein GR, Krok K, et al. A meta-analysis of the placebo rates of remission and response in clinical trials of active Crohn's disease. Gastroenterology 2004; 126:1257-69.

7 Irvine EJ. Assessing outcomes in clinical trials. In: Satsangi J, Sutherland LR, eds. Inflammatory bowel diseases. London: Churchill Livingstone, 2003:319-33.

8 Sandborn WJ, Feagan BG, Hanaver SB, et al. A review of activity indices and efficacy endpoints for clinical trials of medical therapy in adults with Crohn's disease. Gastroenterology 2002; 122:512-30.

9 Brignola C, Campieri M, Bazzocchi G, et al. A laboratory index for predicting relapse in asymptomatic patients with Crohn's disease. Gastroenterology 1986;91:1490-4.

10 Brignola C, lannone P, Pasquali S, et al. Placebo-controlled trial of oral 5-ASA in relapse prevention of Crohn's disease. Dig Dis Sci 1992;37:29-32.

11 Rutgeerts P, D'Haens G, Targan S, et al. Efficacy and safety of retreatment with anti-tumor necrosis factor antibody (infliximab) to maintain remission in Crohn's disease. Gastroenterology 1999;117:761-9.

12 Hanaver SB, Feagan BG, Lichtenstein GR, et al. Maintenance infliximab for Crohn's disease: the ACCENT I randomised trial. Lancet 2002;359:1541-9.

13 Rutgeerts P, Geboes K, Vantrappen G, et al. Predictability of the postoperative course of Crohn's disease. Gastroenterology 1990;99:956-63

14 Caprilli R, Andreoli A, Capurso L, Gruppo Italiano per lo Studio del Colon e del Retto (GISC), et al. Oral mesalazine (5-aminosalicylic acid; Asacol) for the prevention of post-operative recurrence of CD. Aliment Pharmacol Ther 1994:8:35-43

15 Loftus EV Jr. Clinical epidemiology of inflammatory bowel disease: Incidence, prevalence, and environmental influences. Gastroenterology 2004; 126:1504-17.

16 Sands BE. From symptom to diagnosis: clinical distinctions among various forms of intestinal inflammation. Gastroenterology 2004; 126:1518-32

17 Lennard-Jones JE, Shivananda S, the EC-IBD Study Group. Clinical uniformity of inflammatory bowel disease at presentation and during the first year of disease in the north and south of Europe. Eur J Gastroenterol Hepatol 1997;9:353-9

18 American Gastroenterological Association medical position statement. Guidelines for the evaluation and management of chronic diarrhea. Gastroenterology 1999;116:1461-3.

19 Farmer RG, Hawk WA, Turnbull RB Jr. Clinical patterns in Crohns disease: a statistical study of 615 cases. Gastroenterology 1975;68:627-35.

20 Schwartz DA, Loftus EV Jr, Tremaine WJ, et al. The natural history of fistulizing Crohn's disease in Olmsted County, Minnesota. Gastroenterology $2002 ; 122: 875-80$.

21 Jones JH, Lennard-Jones JE, Morson BC, et al. Numerical taxonomy and discriminant analysis applied to non-specific colitis. Q J Med 1973:42:715-32.

22 Greenstein AJ, Lachman P, Sachar DB, et al. Perforating and nonperforating indications for repeated operations in Crohn's disease: evidence for two clinical forms. Gut 1988;29:588-92.

23 Crohn BB, Ginzburg L, Oppenheimer GD. Regional ileitis. J Am Med Assoc 1932:99:1323-9.

24 Crohn BB, Rosenak BD. A combined form of ileitis and colitis. J Am Med Assoc 1936;106:1-7.

25 Brooke BN. Granulomatous diseases of the intestine. Lancet 1959;ii:745-9.

26 Podolsky DK. Inflammatory bowel disease (1). N Engl J Med 1991;325:928-37.

27 Price AB. Overlap in the spectrum of non-specific inflammatory bowel disease-'colitis indeterminate'. J Clin Pathol 1978;31:567-77.

28 Bridger S, Lee JC, Bjarnason I, et al. In siblings with similar genetic susceptibility for inflammatory bowel disease, smokers tend to develop 
Crohn's disease and non-smokers develop ulcerative colitis. Gut 2002;51:21-5.

29 Andersson RE, Olaison G, Tysk C, et al. Appendectomy is followed by increased risk of Crohn's disease. Gastroenterology 2003; 124:40-6

30 Reinisch W, Miehsler W, Dejaco C, et al. An open-label trial of the selective cyclo-oxygenase-2 inhibitor, rofecoxib, in inflammatory bowel diseaseassociated peripheral arthritis and arthralgia. Aliment Pharmacol Ther 2003;17:1371-80

31 Fagan EA, Dyck RF, Maton PN, et al. Serum levels of C-reactive protein in Crohn's disease and ulcerative colitis. Eur I Clin Invest 1982:12:351-9.

32 Vermeire S, Van Assche G, Rutgeerts P. C-reactive protein as a marker for inflammatory bowel disease. Inflamm Bowel Dis 2004;10:661-5.

33 Nielsen $\mathrm{OH}$, Vainer B, Madsen SM, et al. Established and emerging biological activity markers of inflammatory bowel disease. Am J Gastroenterol 2000;95:359-67.

34 Shine B, Berghouse L, Jones JE, et al. C-reactive protein as an aid in the differentiation of functional and inflammatory bowel disorders. Clin Chim Acta 1985; 148:105-9.

35 Beattie RM, Walker-Smith JA, Murch SH. Indications for investigation of chronic gastrointestinal symptoms. Arch Dis Child 1995;73:354-5.

36 Poullis AP, Zar S, Sundaram KK, et al. A new, highly sensitive assay for Creactive protein can aid the differentiation of inflammatory bowel disorders from constipation- and diarrhoea-predominant functional bowel disorders. Eur J Gastroenterol Hepatol 2002;14:409-12.

37 Sachar DB, Luppescu NE, Bodian C, et al. Erythrocyte sedimentation as a measure of Crohn's disease activity: opposite trends in ileitis versus colitis. J Clin Gastroenterol 1990;12:643-6.

38 Mylonaki M, Langmead L, Pantes A, et al. Enteric infection in relapse of inflammatory bowel disease: importance of microbiological examination of stool. Eur J Gastroenterol Hepatol 2004;16:775-8.

39 Geboes $\mathrm{K}$, Ectors $\mathrm{N}, \mathrm{D}^{\prime}$ Haens $\mathrm{G}$, et al. Is ileoscopy with biopsy worthwhile in patients presenting with symptoms of inflammatory bowel disease? Am J Gastroenterol 1998;93:201-6.

40 Coremans G, Rutgeerts P, Geboes K, et al. The value of ileoscopy with biopsy in the diagnosis of intestinal Crohn's disease. Gastrointest Endosc 1984;30:167-72.

41 Pera A, Bellando P, Caldera D, et al. Colonoscopy in inflammatory bowel disease. Diagnostic accuracy and proposal of an endoscopic score. Gastroenterology 1987;92:181-5.

42 Cherian S, Singh P. Is routine ileoscopy useful? An observational study of procedure times, diagnostic yield, and learning curve. Am J Gastroenterol 2004:99:2324-9.

43 Nahon S, Bouhnik Y, Lavergne-Slove A, et al. Colonoscopy accurately predicts the anatomical severity of colonic Crohn's disease attacks: correlation with findings from colectomy specimens. Am J Gastroenterol 2002;97:3102-7.

44 Lipson A, Bartram Cl, Williams CB, et al. Barium studies and ileoscopy compared in children with suspected Crohn's disease. Clin Radiol 1990:41:5-8.

45 Tribl B, Turetschek K, Mostbeck G, et al. Conflicting results of ileoscopy and small bowel double-contrast barium examination in patients with Crohn's disease. Endoscopy 1998;30:339-44.

46 Marshall JK, Cawdron R, Zealley I, et al. Prospective comparison of small bowel meal with pneumocolon versus ileo-colonoscopy for the diagnosis of ileal Crohn's disease. Am J Gastroenterol 2004;99:1321-9.

47 Perez-Cuadrado E, Macenlle R, Iglesias J, et al. Usefulness of oral video push enteroscopy in Crohn's disease. Endoscopy 1997;29:745-7.

48 Halligan S, Saunders B, Williams C, et al. Adult Crohn disease: can ileoscopy replace small bowel radiology? Abdom Imaging 1998:23:117-21.

49 Lauenstein TC, Schneemann H, Vogt FM, et al. Optimization of oral contrast agents for MR imaging of the small bowel. Radiology 2003;228:279-83

50 Wold PB, Fletcher JG, Johnson CD, et al. Assessment of small bowel Crohn disease: noninvasive peroral CT enterography compared with other imaging methods and endoscop--feasibility study. Radiology 2003;229:275-81

51 Maglinte DD, Chernish SM, Kelvin FM, et al. Crohn disease of the small intestine: accuracy and relevance of enteroclysis. Radiology 1992; 184:541-5.

52 Cirillo LC, Camera L, Della NM, et al. Accuracy of enteroclysis in Crohn's disease of the small bowel: a retrospective study. Eur Radiol 2000;10:1894-8.

53 Barloon TJ, Lu CC, Honda H, et al. Does a normal small-bowel enteroclysis exclude small-bowel disease? A long-term follow-up of consecutive normal studies. Abdom Imaging 1994;19:113-15.

54 Toms AP, Barltrop A, Freeman AH. A prospective randomised study comparing enteroclysis with small bowel follow-through examinations in 244 patients. Eur Radiol 2001;11:1155-60.

55 Bernstein CN, Boult IF, Greenberg HM, et al. A prospective randomized comparison between small bowel enteroclysis and small bowel follow-through in Crohn's disease. Gastroenterology 1997;113:390-8.

56 Bozkurt T, Richter F, Lux G. Ultrasonography as a primary diagnostic tool in patients with inflammatory disease and tumors of the small intestine and large bowel. J Clin Ultrasound 1994;22:85-91.
57 Sheridan MB, Nicholson DA, Martin DF. Transabdominal ultrasonography as the primary investigation in patients with suspected Crohn's disease or recurrence: a prospective study. Clin Radiol 1993;48:402-4.

58 Solvig J, Ekberg O, Lindgren S, et al. Ultrasound examination of the small bowel: comparison with enteroclysis in patients with Crohn disease. Abdom Imaging 1995;20:323-6.

59 Tarian Z, Toth G, Gyorke T, et al. Ultrasound in Crohn's disease of the small bowel. Eur J Radiol 2000;35:176-82.

60 Bremner AR, Pridgeon J, Fairhurst J, et al. Ultrasound scanning may reduce the need for barium radiology in the assessment of small-bowel Crohn's disease. Acta Paediatr 2004;93:479-81.

61 Rollandi GA, Curone PF, Biscaldi E, et al. Spiral CT of the abdomen after distention of small bowel loops with transparent enema in patients with Crohn's disease. Abdom Imaging 1999;24:544-9.

62 Raptopoulos V, Schwartz RK, McNicholas MM, et al. Multiplanar helical CT enterography in patients with Crohn's disease. Am J Roentgenol 1997:169:1545-50

63 Rieber A, Wruk D, Potthast S, et al. Diagnostic imaging in Crohn's disease: comparison of magnetic resonance imaging and conventional imaging methods. Int J Colorectal Dis 2000;15:176-81.

64 Schunk K, Kern A, Oberholzer K, et al. Hydro-MRI in Crohn's disease: appraisal of disease activity. Invest Radiol 2000;35:431-7.

65 Maccioni F, Viscido A, Broglia L, et al. Evaluation of Crohn disease activity with magnetic resonance imaging. Abdom Imaging 2000;25:219-28.

66 Giaffer MH. Labelled leucocyte scintigraphy in inflammatory bowel disease: clinical applications. Gut 1996;38:1-5.

67 Scotiniotis I, Rubesin SE, Ginsberg G. Imaging modalities in inflammatory bowel disease. Gastroenterol Clin N Am 1999:28:391-421.

68 Gasche C, Scholmerich J, Brynskov J, et al. A simple classification of Crohn's disease: report of the Working Party for the World Congress of Gastroenterology, Vienna 1998. Inflamm Bowel Dis 2000;6:8-15.

69 Maglinte DD, Reyes BL, Harmon BH, et al. Reliability and role of plain film radiography and $\mathrm{CT}$ in the diagnosis of small-bowel obstruction. Am J Roentgenol 1996;167:1451-5.

70 Rohr A, Rohr D, Kuhbacher T, et al. Radiological assessment of small bowel obstructions: Value of conventional enteroclysis and dynamic MRenteroclysis. Rofo 2002;174:1158-64.

71 Parente F, Maconi G, Bollani S, et al. Bowel ultrasound in assessment of Crohn's disease and detection of related small bowel strictures: a prospective comparative study versus $x$ ray and intraoperative findings. Gut 2002:50:490-5

72 Dijkstra J, Reeders JW, Tytgat GN. Idiopathic inflammatory bowel disease: endoscopic-radiologic correlation. Radiology 1995;197:369-75.

73 Ota Y, Matsui T, Ono H, et al. Value of virtual computed tomographic colonography for Crohn's colitis: comparison with endoscopy and barium enema. Abdom Imaging 2003;28:778-83.

74 Tarjan Z, Zagoni T, Gyorke T, et al. Spiral CT colonography in inflammatory bowel disease. Eur J Radiol 2000;35:193-8.

75 Biancone L, Fiori R, Tosti C, et al. Virtual colonoscopy compared with conventional colonoscopy for stricturing postoperative recurrence in Crohn's disease. Inflamm Bowel Dis 2003;9:343-50.

76 Spalinger J, Patriquin H, Miron MC, et al. Doppler US in patients with Crohn disease: vessel density in the diseased bowel reflects disease activity. Radiology 2000;217:787-91.

77 Esteban JM, Aleixandre A, Hurtado MJ, et al. Contrast-enhanced power Doppler ultrasound in the diagnosis and follow-up of inflammatory abdominal masses in Crohn's disease. Eur J Gastroenterol Hepatol 2003;15:253-9

78 Kratzer W, von Tirpitz C, Mason R, et al. Contrast-enhanced power Doppler sonography of the intestinal wall in the differentiation of hypervascularized and hypovascularized intestinal obstructions in patients with Crohn's disease. $J$ Ultrasound Med 2002;21:149-57.

79 Low RN, Francis IR, Politoske D, et al. Crohn's disease evaluation: comparison of contrast-enhanced MR imaging and single-phase helical CT scanning. J Magn Reson Imaging 2000;11:127-35.

80 Koh DM, Miao Y, Chinn RJ, et al. MR imaging evaluation of the activity of Crohn's disease. Am J Roentgenol 2001;177:1325-32.

81 Gasche C, Moser G, Turetschek K, et al. Transabdominal bowel sonography or the detection of intestinal complications in Crohn's disease. Gut 1999;44:112-17.

82 Gore RM, Balthazar EJ, Ghahremani GG, et al. CT features of ulcerative colitis and Crohn's disease. Am J Roentgenol 1996;167:3-15.

83 Rieber A, Nussle K, Reinshagen M, et al. MRI of the abdomen with positive oral contrast agents for the diagnosis of inflammatory small bowel disease. Abdom Imaging 2002;27:394-9.

84 Rieber A, Aschoff A, Nussle K, et al. MRI in the diagnosis of small bowel disease: use of positive and negative oral contrast media in combination with enteroclysis. Eur Radiol 2000;10:1377-82.

85 Potthast S, Rieber A, von Tirpitz C, et al. Ultrasound and magnetic resonance imaging in Crohn's disease: a comparison. Eur Radiol 2002;12:1416-22.

86 Wagtmans MJ, van Hogezand RA, Griffioen G, et al. Crohn's disease of the upper gastrointestinal tract. Neth J Med 1997:50:S2-7.

87 Witte AM, Veenendaal RA, Van Hogezand RA, et al. Crohn's disease of the upper gastrointestinal tract: the value of endoscopic examination. Scand J Gastroenterol Suppl 1998;225:100-5.

88 Rutgeerts P, Onette E, Vantrappen G, et al. Crohn's disease of the stomach and duodenum: A clinical study with emphasis on the value of endoscopy and endoscopic biopsies. Endoscopy 1980;12:288-94. 
89 Eliakim R, Fischer D, Suissa A, et al. Wireless capsule video endoscopy is a superior diagnostic tool in comparison to barium follow-through and computerized tomography in patients with suspected Crohn's disease. Eur J Gastroenterol Hepatol 2003;15:363-7.

90 Fireman Z, Mahajna E, Broide E, et al. Diagnosing small bowel Crohn's disease with wireless capsule endoscopy. Gut 2003;52:390-2.

91 Herrerias JM, Caunedo A, Rodriguez-Tellez M, et al. Capsule endoscopy in patients with suspected Crohn's disease and negative endoscopy. Endoscopy 2003:35:564-8

92 Mow WS, Lo SK, Targan SR, et al. Initial experience with wireless capsule enteroscopy in the diagnosis and management of inflammatory bowe disease. Clin Gastroenterol Hepatol 2004;2:31-40.

93 Hommes DW, van Deventer SJ. Endoscopy in inflammatory bowel diseases. Gastroenterology 2004;126:1561-73.

94 Lescut D, Vanco D, Bonniere $P$, et al. Perioperative endoscopy of the whole small bowel in Crohn's disease. Gut 1993;34:647-9.

95 Whelan G, Farmer RG, Fazio WW, et al. Recurrence after surgery in Crohn's disease. Relationship to location of disease (clinical pattern) and surgical indication. Gastroenterology 1985;88:1826-33.

96 Bentley E, Jenkins D, Campbell F, et al. How could pathologists improve the initial diagnosis of colitis? Evidence from an international workshop. J Clin Pathol 2002;55:955-60.

97 Dejaco C, Osterreicher C, Angelberger S, et al. Diagnosing colitis: a prospective study on essential parameters for reaching a diagnosis. Endoscopy 2003:35:1004-8.

98 Tanaka M, Riddell RH, Saito $\mathrm{H}$, et al. Morphologic criteria applicable to biopsy specimens for effective distinction of inflammatory bowel disease from other forms of colitis and of Crohn's disease from ulcerative colitis. Scan J Gastroenterol 1999;34:55-67.

99 Geboes K, Ectors N, D'Haens G, et al. Is ileoscopy with biopsy worthwhile in patients presenting with symptoms of IBD. Am J Gastroenterol 1998;93:201-6.

100 Jenkins D, Balsitis M, Gallivan S, et al. Guidelines for the initial biopsy diagnosis of suspected chronic idiopathic inflammatory bowel disease. The British Society of Gastroenterology Initiative. J Clin Pathol 1997; 50:93-105.

101 Schumacher G, Kollberg B, Sandstedt B. A prospective study of first attacks of inflammatory bowel disease and infectious colitis. Histologic course during the 1st year after presentation. Scand J Gastroenterol 1994;29:318-32.

102 Seldenrijk CA, Morson BC, Meuwissen SGM, et al. Histopathological evaluation of colonic mucosal biopsy specimens in chronic inflammatory bowel disease: diagnostic implications. Gut 1991;32:1514-20.

103 Theodossi A, Spiegelhalter DJ, Jass J, et al. Observer variation and discriminatory value of biopsy features in inflammatory bowel disease. Gut 1994;35:961-8

104 Surawicz CM. Serial sectioning of a portion of a rectal biopsy detects more focal abnormalities. A prospective study of patients with inflammatory bowel disease. Dig Dis Sci 1982;27:434-6.

105 Goldman H. Colonic mucosal biopsy in inflammatory bowel disease. Surgical Pathology 1991;4:3-23.

106 Von Herbay A. Evidenz-basierte Leitlinien der DGVS für Diagnostik und Therapie beim Morbus Crohn. Z Gastroenterol 2003;41:24-6.

107 Petritsch W, Feichtenschlager T, Gasche C, et al. Diagnosis in chronic inflammatory bowel diseases - report of the Austrian Chronic Inflammatory Bowel Disease Study Group. Acta Med Austriaca 1998;25:37-43.

108 Hahne M, Riemann JF. Inflammatory bowel diseases: diagnosis (including new procedures for small intestine examination). Schweiz Rundsch Med Prax 2002:91:2023-8.

109 Lennard-Jones JE. Crohn's disease: definition, pathogenesis, aetiology. Clin Gastroenterol Suppl 1980;I:173-89.

110 Tanaka M, Saito H, Fukuda S, et al. Simple mucosal biopsy criteria differentiating among Crohn's disease, ulcerative colitis, and other forms of colitis. Measurement of validity. Scand J Gastroenterol 2000;35:281-6.

111 Mahadeva U, Martin JP, Patel NK, et al. Granulomatous ulcerative colitis: a re-appraisal of the mucosal granuloma in the distinction of Crohn's disease from ulcerative colitis. Histopathology 2002;41:50-5.

112 Bernades $P$, Hecketsweiler $P$, Benozio $M$, et al. Proposition d'un système de critères pour le diagnostic des entérocolite inflammatoires cryptogénétiques (maladie de Crohn et Rectocolite Hémorragique). Gastroentérol Clin Biol 1978:2:1047-54.

113 Jenkins D, Goodall A, Drew K, et al. What is colitis? Statistical approach to distinguishing clinically important inflammatory change in rectal biopsy specimens. J Clin Pathol 1988;41:72-9.

114 Kleer CG, Appelman HD. Ulcerative colitis: patterns of involvement in colorectal biopsies and changes with time. Am J Surg Pathol 1998;22:983-9

115 Bernstein CN, Shanahan F, Anton PA, et al. Patchiness of mucosal inflammation in treated ulcerative colitis: a prospective study. Gastrointest Endosc 1995:42:232-7.

116 Geboes K. Pathology of inflammatory bowel diseases (IBD): variability with time and treatment. Colorectal Disease 2001;3:2-12.

117 Markowitz J, Kahn E, Grancher K, et al. Atypical rectosigmoid histology in children with newly diagnosed ulcerative colitis. Am J Gastroenterol 1993;88:2034-7.

118 Robert ME, Tang L, Hao LM, et al. Patterns of inflammation in mucosal biopsies of ulcerative colitis. Perceived differences in pediatric populations are limited to children younger than 10 years. Am J Surg Pathol 2004;28:183-9.
119 Glickman JN, Bousvaros A, Farraye FA, et al. Pediatric patients with untreated ulcerative colitis may present initially with unusual morphologic findings. Am J Surg Pathol 2004;28:190-7.

120 Tanaka M, Riddell RH. The pathological diagnosis and differential diagnosis of Crohn's disease. Hepatogastroenterology 1990;37:18-31.

121 Cook MG, Dixon MF. An analysis of the reliability of detection and diagnostic value of various pathological features in Crohn's disease and ulcerative colitis. Gut 1973;14:255-62.

122 Ectors NL, Dixon MF, Geboes KJ, et al. Granulomatous gastritis: a morphological and diagnostic approach. Histopathology 1993;23:55-61

123 Shapiro JL, Goldblum JR, Petras RE. A clinicopathologic study of 42 patients with granulomatous gastritis. Is there really an idiopathic granulomatous gastritis. Am J Surg Pathol 1996;20:462-70.

124 Oberhuber G, Puspok A, Oesterreicher C, et al. Focally enhanced gastritis: a frequent type of gastritis in patients with Crohn's disease. Gastroenterology 1997; 112:698-706.

125 Wright CL, Riddell RH. Histology of the stomach and duodenum in Crohn's disease. Am J Surg Pathol 1998;22:383-90.

126 Parente F, Cucino C, Bollani S, et al. Focal gastric inflammatory infiltrates in inflammatory bowel diseases: prevalence, immunohistochemical characteristics and diagnostic role. Am J Gastroenterol 2000;95:705-11.

127 Levine D, Reid B. Endoscopic biopsy technique for acquiring larger mucosal samples. Gastrointest Endosc 1991;37:332-7.

128 Rozen P, Baratz M, Fefer F, et al. Low incidence of significant dysplasia in a successful endoscopic surveillance program of patients with ulcerative colitis. Gastroenterology 1995:108:1361-70.

129 Riddell RH, Goldman H, Ransohoff DF, et al. Dysplasia in inflammatory bowel disease: Standardized classification with provisional clinical applications. Hum Pathol 1983;14:931-68.

130 Farmer M, Petras RE, Hunt LE, et al. The importance of diagnostic accuracy in colonic inflammatory bowel disease. Am J Gastroenterol 2000;95:3184-8.

131 Sheehan AL, Warren BF, Gear MW, et al. Fat-wrapping in Crohn's disease: pathological basis and relevance to surgical practice. Br J Surg 1992:79:955-8.

132 Borley NR, Mortensen NJ, Jewell DP, et al. The relationship between inflammatory and serosal connective tissue change in ilea Crohn's disease: evidence for a possible causative link. J Pathol 2000; 190:196-202.

133 Wright R, Truelove SC. Serial rectal biopsy in ulcerative colitis during the course of a controlled therapeutic trial of various diets. Am J Dig Dis 1964; 11:847-57

134 Odze R, Antonioli D, Peppercorn M, et al. Effect of topical 5-amino-salicylic acid (5-ASA) therapy on rectal mucosal biopsy morphology in chronic ulcerative colitis. Am J Surg Pathol 1993;17:869-75.

135 Riley SA, Mani V, Goodman MJ, et al. Microscopic activity in ulcerative colitis: what does it mean? Gut 1991;32:174-8

136 Bitton A, Peppercorn MA, Antonioli DA, et al. Clinical, biological and histologic parameters as predictors of relapse in ulcerative colitis. Gastroenterology 2001;120:13-20.

137 Korelitz BJ, Sommers SC. Response to drug therapy in Crohn's disease: evaluation by rectal biopsy and mucosal cell counts. J Clin Gastroenterol 1984;6:123-7.

138 D'Haens G, Geboes K, Ponette E, et al. Healing of severe recurrent ileitis with azathioprine therapy in patients with Crohn's disease. Gastroenterology 1997;1 12:1475-81

139 D'Haens G, Van Deventer S, Van Hogezand R, et al. Endoscopic and histological healing with infliximab anti-fumor necrosis factor antibodies in Crohn's disease: a European multicenter trial. Gastroenterology 1999; 116:1029-34

140 Nicholls S, Domizio P, Williams CB, et al. Cyclosporin as initial treatment for Crohn's disease. Arch Dis Child 1994:71:243-7.

141 Beattie RM, Schiffrin EJ, Donnet-Hughes A, et al. Polymeric nutrition as the primary therapy in children with small bowel Crohn's disease. Aliment Pharmacol Ther 1994;8:609-15.

142 Breese EJ, Michie CA, Nicholls SW, et al. Tumor necrosis factor alpha producing cells in the intestinal mucosa of children with inflammatory bowel disease. Gastroenterology 1994;106:1455-66.

143 Fell JME, Paintin M, Arnaud-Battandier F, et al. Mucosal healing and a fall in mucosal pro-inflammatory cytokine mRNA induced by a specific oral polymeric diet in paediatric Crohn's disease. Aliment Pharmacol Ther 2000;14:281-9,

144 Bataille F, Klebl F, Rümmele $P$, et al. Histopathological parameters as predictors for the course of Crohn's disease. Virchows Arch 2003:443:501-7.

145 Hugot JP, Chamaillard M, Zouali H, et al. Association of NOD2 leucine-rich repeat variants with susceptibility to Crohn's disease. Nature 2001;411:599-603

146 Ogura Y, Bonen DK, Inohara N, et al. A frameshift mutation in NOD2 associated with susceptibility to Crohn's disease. Nature 2001;411:603-6.

147 Hampe J, Cuthbert A, Croucher PJP, et al. An insertion mutation in the NOD2 gene predisposes to Crohn's Disease in the German and British populations. Lancet 2001;357:1925-8.

148 Hampe J, Grebe J, Nikolaus S, et al. Association of NOD2 (CARD 15) genotype with clinical course of Crohn's disease: a cohort study. Lancet 2002;359:1661-5

149 Cuthbert AP, Fisher SA, Mirza MM, et al. The contribution of NOD2 gene mutations to the risk and site of disease in inflammatory bowel disease. Gastroenterology 2002;122:867-74. 
150 Ahmad T, Armuzzi A, Bunce M, et al. The molecular classification of the clinical manifestations of Crohn's disease. Gastroenterology 2002; 122:854-66.

151 Lesage S, Zouali H, Cezard JP, EPWG-IBD Group, EPIMAD Group, GETAID Group, et al. CARD15/NOD2 mutational analysis and genotype-phenotype correlation in 612 patients with inflammatory bowel disease. Am J Hum Genetics 2002;70:845-57.

152 Radlmayr M, Torok HP, Martin K, et al. The c-insertion mutation of the NOD2 gene is associated with fistulizing and fibrostenotic phenotypes in Crohn's disease. Gastroenterology 2002;122:2091-2.

153 Abreu MT, Taylor KD, Lin YC, et al. Mutations in NOD2 are associated with fibrostenosing disease in patients with Crohn's disease. Gastroenterology 2002; 123:679-88.

154 Stoll M, Corneliussen B, Costello CM, et al. Genetic variation in DLG5 is associated with inflammatory bowel disease. Nat Genetics 2004;36:476-80.

155 Peltekova VD, Wintle RF, Rubin LA, et al. Functional variants of OCTN cation transporter genes are associated with Crohn disease. Nat Genetics 2004:36:471-5.

156 Tibble JA, Sigthorsson G, Bridger S, et al. Surrogate markers of intestinal inflammation are predictive of relapse in patients with inflammatory bowel disease. Gastroenterology 2000;1 19:15-22.

157 Saitoh O, Kojima K, Sugi K, et al. Fecal eosinophil granule-derived proteins reflect disease activity in inflammatory bowel disease. Am J Gastroenterol 1999;94:3513-20.

158 Schreiber S, Nikolaus S, Hampe J, et al. Tumor necrosis factor- $\alpha$ and interleukin $1 \beta$ in relapse of Crohn's disease. Lancet 1999;353:459-61.
159 Peeters M, Joossens S, Vermeire S, et al. Diagnostic value of anti-Saccharomyces cerevisiae and antineutrophil cytoplasmic autoantibodies in inflammatory bowel disease. Am J Gastroenterol 2001;96:730-4.

160 Brignola C, Lanfranchi GA, Campieri M, et al. Importance of laboratory parameters in the evaluation of Crohn's disease activity. J Clin Gastroenterol 1986;8:245-8

161 Consigny Y, Modigliani R, Colombel JF, et al. Biological markers of shortterm relapse in Crohn's disease (CD). Gastroenterology 2001;120(suppl):A141.

162 Hollander D, Vadheim CM, Brettholz E, et al. Increased intestinal permeability in patients with Crohn's disease and their relatives. A possible etiologic factor. Ann Intern Med 1986;105:883-5.

163 Wyatt J, Vogelsang H, Hubl W, et al. Intestinal permeability and the prediction of relapse in Crohn's disease. Lancet 1993;341:1437-9.

164 Louis E, Collard A, Oger AF, et al. Behaviour of Crohn's disease according to the Vienna classification: changing pattern over the course of the disease. Gut 2001;49:777-82.

165 Silverberg MS, Satsangi J, Ahmad T, et al. Toward an integrated clinical, molecular and serological classification of inflammatory bowel disease: Report of a working party of the 2005 Montreal World Congress of Gastroenterology. Can J Gastroenterol 2005; 19(suppl A):5-36.

166 Boirivant M, Leoni M, Tariciotti D, et al. The clinical significance of serum $C$ reactive protein levels in Crohn's disease. Results of a prospective longitudinal study. J Clin Gastroenterol $1988 ; 10: 401-5$. 